\title{
How Does Hubei Province Restructure Its Industrial Structure?
}

\author{
Gui-Zhi BA ${ }^{a, *}$, Han WANG ${ }^{b}$
}

School of Economics and Management, China University of Geosciences, Wuhan 430074, China

abguizhi@163.com, b1073058026@qq.com

${ }^{*}$ Corresponding author

Keywords: Input-output analysis; industrial structure; correlation feature; Hubei province

\begin{abstract}
Industrial structure restructuring is one of the main features that measure the development of national economy. Input-output analysis on industrial structure is a vital method to investigate industrial inner mechanism. Therefore, to restructure the industrial structure in Hubei Province, the input-output analysis has been implemented. Results show that the influence coefficient of heavy chemical sectors and light manufacturing industries is relatively large. The stimulating effect of consumer is relatively comprehensive to sectors in Hubei. And the investment mainly stimulates the heavy chemical sectors and manufacturing industries. Furthermore, according to the focused industries from "Twelfth Five-Year Plan" in Hubei, secondary industry still accounts for too large after the simulative adjustments of industrial structure, so the industrial structure is not completely rational.
\end{abstract}

\section{Introduction}

After the strategic adjustment of industrial structure during "Tenth Five-Year" and "Eleventh Five-Year" period, there was greater change of industrial structure in Hubei province, but low level of industrial structure was still the root cause of contradictions and problems in economic operation in Hubei Province. To achieve a high degree of industrial structure is the main task of industrial structure adjustment in Hubei province.

At present, the main methods to adjust industrial structure are gray theory, avenue model, mathematical programming, computable general equilibrium model (CGE), econometric methods and input-output analysis method,and so forth[1]. But these models are merely to make relative comparison and analysis of historical data to get relative values, so they are just relative evaluations. Input-output method, involves the industry economics and is based on practical industrial structure, which can avoid the impact of single adjustment of industrial structure on economic system stability. At present, studies applying input-output method to explore industrial structure optimization are mainly in the following aspects: (1) correlation characteristics of industrial structure analyze [2,3], (2) industrial structure changes esitmation combining input-output method with other methods [4,5]; (3) industrial structure optimization $[6,7,8]$.

The input-output method is extensively applied by scholars in the study of industrial structure optimization, however, relevant researches about how to specifically adjust industrial structures of specific economies are still relatively few. Based on this, this paper draws on the input-output tables of the year of 2002 and 2007 in Hubei, analyzes the industry structure correlation degree among 42 sectors in Hubei province, and investigates the changes of some sectors' total output caused the changes of industry structure, and then put forward a thinking of industrial restructuring, which is closer to reality and better conforms to economic logic.

\section{Present industrial structure of Hubei province and input-output analysis}

\section{Study on the current situation of industrial structure development in Hubei province}

According to the Statistical Yearbook of Hubei Province in 2012, the industrial structure 
proportion further adjusts from 35.7: 46: 18.3 in 1980 to 13.1: 50.0: 36.9 in 2011, with the proportion of the tertiary industry declining. The results are shown in Fig.1: the proportion of primary industry gradually dropped from $35.7 \%$ in 1980 to $13.1 \%$ in 2011 , which was relegated to second place in the province's economy; the secondary industry was $46 \%$ in 1980 and fluctuated between $37 \%$ and $45 \%$ afterwards. The proportion of the second industry was $50 \%$ in 2011 , still being dominant, which indicated that Hubei's economy had entered a period of inside adjustment of the secondary industry, but was still in the process of industrialization. Tertiary industry basically maintained an upward trend, rising from $18.3 \%$ in 1980 to $40.8 \%$ in 2000 , being steady at around $40 \%$ level afterwards, which developed rapidly.

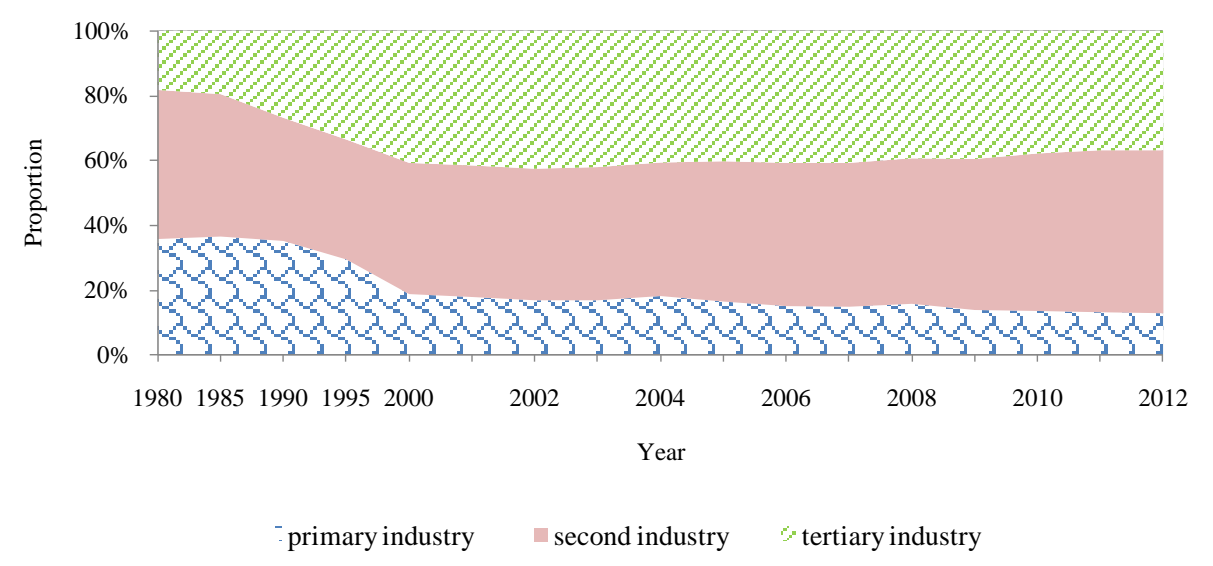

Fig. 1 Three industries of GDP in Hubei province (1980-2011)

\section{Method: Input-Output Analysis}

There are interrelations between each industry of national economy, the changes of one industry will affect the other industries related to it [9].

(1) Direct consumption coefficient and complete consumption coefficient

Direct consumption coefficient is denoted by $a_{i j}$, the matrix of it is denoted by $A$, which is calculated as follows:

$$
a_{i j}=x_{i j} / X_{j} \quad(i, j=1,2, \ldots, n)
$$

Complete consumption coefficient is denoted by $b_{i j}$, the matrix of it is usually represented by $B$, the calculation formula is:

$$
B=(I-A)^{-1}
$$

(2)Influence coefficient and sensitivity coefficient

Influence coefficient is calculated as:

$$
m_{j}=\frac{\sum_{i=1}^{n} b_{i j}}{\frac{1}{n} \sum_{j=1}^{n} \sum_{i=1}^{n} b_{i j}} \quad(j=1,2, \ldots, n)
$$

Where the numerator is the sum of the $\mathrm{j}$-th column of $(I-A)^{-1}$ and the denominator is the average of the columns of $(I-A)^{-1}$.

Sensitivity coefficient is calculated as: 


$$
n_{i}=\frac{\sum_{j=1}^{n} b_{i j}}{\frac{1}{n} \sum_{i=1}^{n} \sum_{j=1}^{n} b_{i j}} \quad(i=1,2, \ldots, n)
$$

Where the numerator is the sum of the $\mathrm{i}$-th row of $(I-A)^{-1}$ and the denominator is the average of $(I-A)^{-1}$.

(3) Production induced coefficient of final demand

Production induced value can be calculated by the following formula:

$$
X=(I-A)^{-1} F
$$

Where $X$ is the final demand for the production of induced vector, $F$ is the final demand vector.

Production induced coefficient of final demand $=$ the final demand for the production induced value/the corresponding sum of final demand

(4) Dependence on final demand of sectors

Dependence on final demand of sectors $=$ the final demand for the production induced value/sum of the final demand for the production induced value of the industrial sector

\section{Results and analysis}

\section{Analysis of the extent of industry association spread}

Table 1 shows that sectors with larger influence coefficient are mostly heavy chemical sectors, led by heavy industry in the 19th century, especially the military industry, industrial structure in Hubei tends to be heavy-duty. What follows is the light manufacturing sector, which is a traditional pillar industry and important livelihood industry in Hubei province. Electronic and mechanical processing and assembly sectors like non-metallic mineral products manufacturing(S13), transport equipment manufacturing(S17), communications equipment, computers and other electronic equipment manufacturing(S19) developed rapidly, which indicates that these sectors play an important role in boosting the economy, so key sectors and sectors with priority to develop can be determined in order to rationalize the industrial structure. From the sensitivity coefficient, the sectors with large sensitivity coefficient are: chemical industry (S12), metal smelting and rolling processing industry (S14), farming, forest, herd and fishery (S1) and other sectors, which indicates that these sectors are in great demand in Hubei Province. 
Table 1.Influence coefficient, sensitivity coefficient and the induced degree of all departments of Hubei province in 2007.

\begin{tabular}{|c|c|c|c|c|c|c|c|c|c|c|c|}
\hline \multirow[b]{2}{*}{ sector } & \multirow{2}{*}{$\begin{array}{l}\text { sensitivity } \\
\text { coefficient }\end{array}$} & \multirow{2}{*}{$\begin{array}{l}\text { influence } \\
\text { coefficient }\end{array}$} & \multicolumn{3}{|c|}{ induced degree } & \multirow[b]{2}{*}{ sector } & \multirow{2}{*}{$\begin{array}{l}\text { sensitivity } \\
\text { coefficient }\end{array}$} & \multirow{2}{*}{$\begin{array}{l}\text { influence } \\
\text { coefficient }\end{array}$} & \multicolumn{3}{|c|}{ induced degree } \\
\hline & & & consumption & investment & export & & & & consumption & investment & export \\
\hline S1 & 1.84 & 0.83 & 0.281 & 0.120 & 0.346 & S22 & 0.50 & 0.63 & 0.002 & 0.004 & 0.004 \\
\hline S2 & 0.99 & 0.98 & 0.022 & 0.031 & 0.035 & $\mathrm{~S} 23$ & 1.51 & 0.89 & 0.058 & 0.057 & 0.096 \\
\hline S3 & 1.00 & 0.99 & 0.024 & 0.023 & 0.026 & S24 & 0.66 & 0.74 & 0.036 & 0.012 & 0.009 \\
\hline S4 & 0.72 & 1.23 & 0.008 & 0.026 & 0.023 & S 25 & 0.63 & 1.03 & 0.009 & 0.008 & 0.008 \\
\hline S5 & 0.75 & 1.34 & 0.011 & 0.030 & 0.014 & S26 & 0.76 & 1.27 & 0.032 & 0.384 & 0.012 \\
\hline S6 & 1.22 & 1.07 & 0.294 & 0.042 & 0.204 & S27 & 1.43 & 0.97 & 0.064 & 0.118 & 0.157 \\
\hline S7 & 1.21 & 1.25 & 0.092 & 0.016 & 0.192 & $\mathrm{~S} 28$ & 0.49 & 0.91 & 0.002 & 0.004 & 0.002 \\
\hline S8 & 0.74 & 1.24 & 0.076 & 0.016 & 0.057 & $\mathrm{~S} 29$ & 0.70 & 0.73 & 0.026 & 0.038 & 0.017 \\
\hline $\mathrm{S} 9$ & 0.79 & 1.11 & 0.019 & 0.037 & 0.018 & $\mathrm{~S} 30$ & 1.39 & 0.67 & 0.050 & 0.158 & 0.123 \\
\hline $\mathrm{S} 10$ & 1.58 & 1.26 & 0.068 & 0.039 & 0.049 & $\mathrm{~S} 31$ & 0.92 & 1 & 0.086 & 0.018 & 0.028 \\
\hline S11 & 1.43 & 1.32 & 0.046 & 0.058 & 0.065 & $\mathrm{~S} 32$ & 1.16 & 0.76 & 0.042 & 0.069 & 0.039 \\
\hline $\mathrm{S} 12$ & 2.53 & 1.18 & 0.159 & 0.117 & 0.203 & S 33 & 1.35 & 0.73 & 0.039 & 0.080 & 0.048 \\
\hline $\mathrm{S} 13$ & 1.15 & 1.16 & 0.043 & 0.101 & 0.087 & S34 & 0.88 & 1.03 & 0.027 & 0.020 & 0.026 \\
\hline S14 & 1.93 & 1.21 & 0.042 & 0.178 & 0.154 & S35 & 0.51 & 0.88 & 0.006 & 0.004 & 0.003 \\
\hline S15 & 1.39 & 1.15 & 0.031 & 0.073 & 0.058 & S36 & 0.78 & 0.87 & 0.013 & 0.011 & 0.012 \\
\hline S16 & 1.07 & 1.11 & 0.025 & 0.170 & 0.055 & S37 & 0.61 & 0.69 & 0.013 & 0.002 & 0.002 \\
\hline S17 & 0.74 & 1.13 & 0.018 & 0.178 & 0.066 & S38 & 1.07 & 0.85 & 0.034 & 0.028 & 0.028 \\
\hline S18 & 0.81 & 1.08 & 0.022 & 0.042 & 0.030 & S39 & 0.69 & 0.73 & 0.125 & 0.011 & 0.009 \\
\hline S19 & 0.89 & 1.03 & 0.038 & 0.066 & 0.017 & $\mathrm{~S} 40$ & 0.83 & 0.95 & 0.053 & 0.015 & 0.013 \\
\hline $\mathrm{S} 20$ & 0.62 & 1.09 & 0.006 & 0.017 & 0.010 & S41 & 0.68 & 0.87 & 0.018 & 0.009 & 0.007 \\
\hline $\mathrm{S} 21$ & 0.59 & 1.29 & 0.008 & 0.014 & 0.008 & $\mathrm{~S} 42$ & 0.46 & 0.74 & 0.128 & 0.001 & 0.001 \\
\hline
\end{tabular}

\section{Production induced degree of the final demand}

As shown in the latter part of table 1, from the view of consumer spending induced coefficient in 2007, the manufacture of foods and tobacco (S6), farming, forest, herd and fishery (S1), chemical industry (S12) and other sectors have a higher induced degree. From the view of investment demand induced coefficient, the tops are: construction (S26), smelting and processing of metals (S14), manufacture of transportation equipment (S17) etc. From the view of export induced coefficient, farming, forest, herd and fishery (S1), the manufacture of foods and tobacco (S6), chemical industry (S12) and other sectors have a higher induced coefficient, which reflects that these sectors have a higher dependence on exports.

\section{Dependence on final demand of sectors}

From Table 2 it can be concluded that (as shown in Table 3): From a dynamic point of view, sectors whose consumer demand dependence had a great increase from 2002 to 2007 are construction(S26), manufacture of non-metal mineral products(S13), manufacture of communication equipment, computers and other electronic equipment(S19) and so on. Most sectors' investment dependence rose up. The sectors whose export dependence rose up are post, integrated technical services leasing and commercial services etc.

\section{Industrial structure restructuring caused by sectors' final product changes}

Develop strategic emerging industries vigorously, promote advanced manufacturing, and accelerate the development of modern service industry will be the main direction of industrial restructuring in Hubei province [10]. According to the "Twelfth Five Year Plan", the focused sectors to be fostered and developed in Hubei province are information transmission, computer services and software(S29), manufacture of communication equipment, computers and other electronic equipment(S19), smelting and processing of metals(S14), manufacture of transportation equipment(S17) and so on, corresponding to the input-output table. Selecting the smelting and processing of metals(S14), manufacture of communication equipment, computers and other electronic equipment(S19), and transportation and storage(S27) these three priority sectors as 
examples, this paper explores how other sectors change when the final product of these three sectors changes. To solve the problem of how $X$ changes after the changes of $Y$, the following formula is given[11]:

$$
\Delta X=(I-A)^{-1} \Delta Y
$$

Where $X$ is the column vector of sectors' total output $Y$, is the column vector of sectors' final use.

This paper assumes that the final use of other sectors are fixed, based on the total industrial output value of smelting and processing of metals(S14) and manufacture of communication equipment, computers and other electronic equipment (S19)from Statistical Yearbook, annual average growth rates excluding the factor of price are calculated, and the predicted growth rate of the two sectors are $35 \%$ and $60 \%$,respectively. The growth rate of transportation and storage (S27) is estimated as $10 \%$ according to Hubei Provincial Bureau of Statistics, so the results of the corresponding 42 sectors' output changes are shown in the latter part of Table 2 . According to the results, the output of manufacture of metal products (S15) increased $0.099 \%$ after the adjustment, which is the largest increased proportion. Secondly, the increased proportions of processing of petroleum, coking and the mining industry (S11) were more than $0.05 \%$. However, the proportions of farming, forest, herd and fishery (S1) and construction (S26) decreased greatly, which were more than $0.25 \%$.

Table 2. The change of production dependence and the total output of final demand of Hubei province sectors in 2007

\begin{tabular}{|c|c|c|c|c|c|c|c|c|c|c|c|c|c|}
\hline \multirow[b]{2}{*}{ sector } & \multicolumn{3}{|c|}{ dependence } & \multicolumn{3}{|c|}{ The changes of total output } & \multirow[b]{2}{*}{ sector } & \multicolumn{3}{|c|}{ dependence } & \multicolumn{3}{|c|}{ The changes of total output } \\
\hline & consumption & investment & export & $\begin{array}{l}\text { The initial } \\
\text { total output } \\
\text { proportion } \\
\text { (\%) }\end{array}$ & $\begin{array}{l}\text { The total output } \\
\text { proportion after } \\
\text { changes }(\%)\end{array}$ & $\begin{array}{l}\text { Incremental } \\
\text { amplitude (\%) }\end{array}$ & & consumption & investment & export & $\begin{array}{l}\text { The initial } \\
\text { total output } \\
\text { proportion } \\
(\%)\end{array}$ & $\begin{array}{l}\text { The total output } \\
\text { proportion after } \\
\text { changes (\%) }\end{array}$ & $\begin{array}{c}\text { Incremental } \\
\text { amplitude } \\
(\%)\end{array}$ \\
\hline \$1 & 0.52 & 0.20 & 0.28 & 10.54 & 10.24 & -0.30 & \$22 & 0.32 & 0.45 & 0.24 & 0.13 & 0.13 & 0.00 \\
\hline S2 & 0.34 & 0.43 & 0.23 & 0.11 & 0.16 & 0.04 & \$23 & 0.39 & 0.34 & 0.27 & 2.74 & 2.74 & -0.01 \\
\hline \$3 & 0.44 & 0.36 & 0.20 & 0.08 & 0.11 & 0.03 & \$24 & 0.72 & 0.21 & 0.08 & 1.11 & 1.08 & -0.03 \\
\hline \$4 & 0.19 & 0.57 & 0.24 & 0.40 & 0.45 & 0.05 & S25 & 0.45 & 0.36 & 0.19 & 0.32 & 0.32 & 0.00 \\
\hline S5 & 0.24 & 0.62 & 0.14 & 0.74 & 0.73 & -0.01 & \$26 & 0.09 & 0.90 & 0.01 & 8.57 & 8.32 & -0.25 \\
\hline S6 & 0.70 & 0.09 & 0.21 & 8.13 & 7.91 & -0.23 & \$27 & 0.27 & 0.45 & 0.28 & 4.39 & 4.59 & 0.20 \\
\hline S7 & 0.49 & 0.08 & 0.44 & 3.60 & 3.50 & -0.10 & \$28 & 0.37 & 0.50 & 0.12 & 0.12 & 0.12 & 0.00 \\
\hline S8 & 0.67 & 0.12 & 0.21 & 2.44 & 2.38 & -0.06 & S29 & 0.39 & 0.50 & 0.11 & 1.38 & 1.36 & -0.02 \\
\hline \$9 & 0.31 & 0.56 & 0.13 & 1.08 & 1.06 & -0.02 & $\$ 30$ & 0.21 & 0.58 & 0.22 & 4.65 & 4.58 & -0.08 \\
\hline S10 & 0.55 & 0.28 & 0.17 & 1.70 & 1.68 & -0.02 & \$31 & 0.76 & 0.14 & 0.11 & 2.39 & 2.34 & -0.06 \\
\hline S11 & 0.37 & 0.41 & 0.22 & 1.24 & 1.30 & 0.06 & \$32 & 0.35 & 0.51 & 0.14 & 2.34 & 2.31 & -0.03 \\
\hline $\mathrm{S} 12$ & 0.45 & 0.30 & 0.25 & 5.73 & 5.64 & -0.09 & S33 & 0.30 & 0.54 & 0.16 & 2.48 & 2.50 & 0.01 \\
\hline $\mathrm{S} 13$ & 0.25 & 0.53 & 0.22 & 3.14 & 3.10 & -0.05 & \$34 & 0.48 & 0.32 & 0.20 & 1.07 & 1.06 & -0.01 \\
\hline S14 & 0.16 & 0.60 & 0.25 & 4.59 & 4.89 & 0.30 & \$35 & 0.52 & 0.34 & 0.14 & 0.21 & 0.21 & 0.00 \\
\hline S15 & 0.26 & 0.54 & 0.21 & 2.24 & 2.34 & 0.10 & S36 & 0.47 & 0.35 & 0.18 & 0.53 & 0.53 & 0.00 \\
\hline S16 & 0.13 & 0.76 & 0.12 & 3.63 & 3.55 & -0.07 & S37 & 0.83 & 0.11 & 0.06 & 0.34 & 0.33 & -0.01 \\
\hline S17 & 0.09 & 0.77 & 0.14 & 4.30 & 4.20 & -0.10 & \$38 & 0.48 & 0.35 & 0.17 & 1.30 & 1.30 & 0.00 \\
\hline S18 & 0.31 & 0.51 & 0.18 & 1.36 & 1.36 & -0.01 & $\$ 39$ & 0.90 & 0.07 & 0.03 & 3.07 & 2.99 & -0.08 \\
\hline S19 & 0.37 & 0.56 & 0.07 & 1.88 & 2.84 & 0.95 & $\$ 40$ & 0.74 & 0.18 & 0.08 & 1.44 & 1.42 & -0.02 \\
\hline $\mathrm{S} 20$ & 0.24 & 0.60 & 0.16 & 0.43 & 0.42 & 0.00 & S41 & 0.63 & 0.27 & 0.10 & 0.58 & 0.57 & -0.01 \\
\hline S21 & 0.34 & 0.51 & 0.14 & 0.49 & 0.48 & -0.01 & $\$ 42$ & 0.99 & 0.01 & 0.00 & 2.97 & 2.88 & -0.09 \\
\hline
\end{tabular}


Table 3 Sector classification that is highly dependent on consumption, investment and export

\begin{tabular}{ll}
\hline \multicolumn{1}{c}{ Clusters } & \multicolumn{1}{c}{ Sector } \\
\hline $\begin{array}{l}\text { Highly dependent on } \\
\text { consumer }\end{array}$ & $\begin{array}{l}\text { Manufacture of Paper, Printing, Articles for Culture,Sport(S10), Research } \\
\text { and Experimental Development(S35), Farming, Forest, Herd and } \\
\text { Fishery(S1) (More than 50\%); Manufacture of Textile(S7), Resident } \\
\text { Service and Others(S38), Leasing and Commerical Services(S34) etc. } \\
\text { (more than 40\%) }\end{array}$ \\
\hline $\begin{array}{l}\text { Highly dependent on } \\
\text { investment }\end{array}$ & $\begin{array}{l}\text { Wimber and Manufacture of Furniture (S9)etc. (more than 50\%); Post(S28), } \\
\text { Information Transmission, Computer Services and Software(S29), }\end{array}$ \\
\hline Transportation and storage(S27) etc. (more than 40\%); \\
\hline Highly dependent on \\
export & $\begin{array}{l}\text { Manufacture of Textile(S7) ( up to 44\%); Farming, Forest, Herd and } \\
\text { Fishery(S1), Transportation and storage(S27), Production and Supply of } \\
\text { Electric Power and Heat Power(S23) etc. (more than 20\%). }\end{array}$ \\
\hline
\end{tabular}

To make the results clearer, eight sectors which rise and fall most sharply are selected, the results are as shown in Fig. 2. From Fig. 2, it can be seen that if the above three sectors are developed as focuses, the total output of manufacture of metal products(S15), processing of petroleum, coking and nuclear fuel, metal mining(S11) industry should be elevated, and the proportion of farming, forest, herd and fishery (S1) and construction (S26) should be reduced.

From the components of the changes in three industries, the proportion of the primary industry and the tertiary industry will drop $0.296 \%$ and $0.192 \%$, respectively; the proportion of the secondary industry will rise by $0.488 \%$. It can be seen that the second industry still dominates in Hubei province, while the tertiary industry has a small decline, the industrial structure is not completely rational and still need to be adjusted. Changes of tertiary industry after the further adjustments can been seen in Fig. 3, only the proportion of the real estate and resident service and other services increased in the tertiary industry, the rise rate are $0.013 \%$ and $0.004 \%$, respectively. The proportion of the rest sectors declined, especially in public management and social organization, education, wholesale and retail sale and so on, decrease by $0.07 \%$. It can be seen that although Hubei province was committed to adjust and optimize the industrial structure, and increased the investment on the tertiary industry gradually, but the proportion of secondary industry is still too large, restrict the development of the tertiary industry.

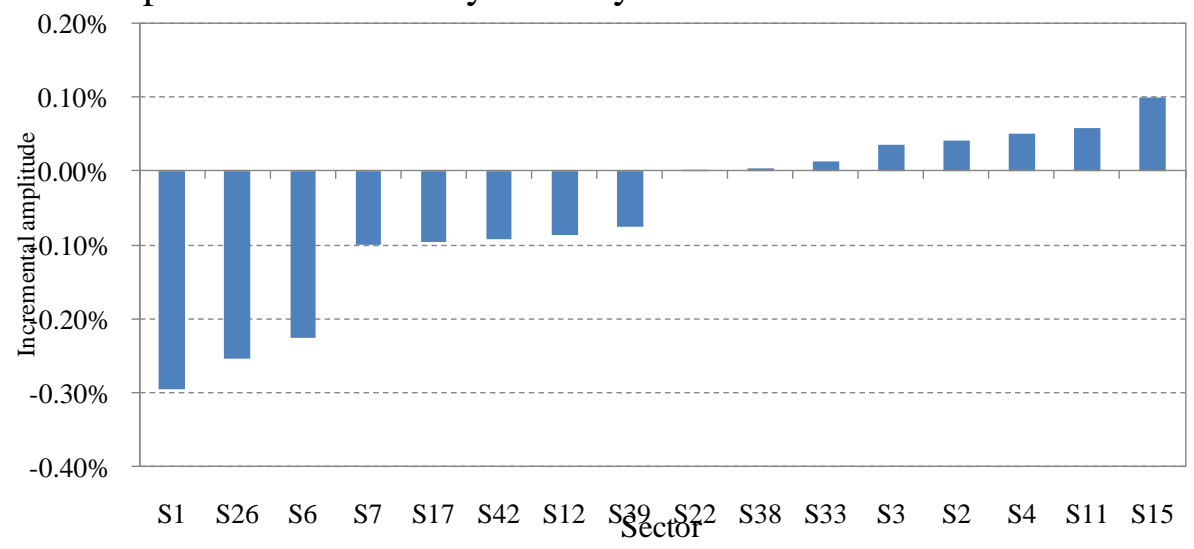

Fig. 2 The output changes of other sectors caused by the changes of the three sectors' final product 


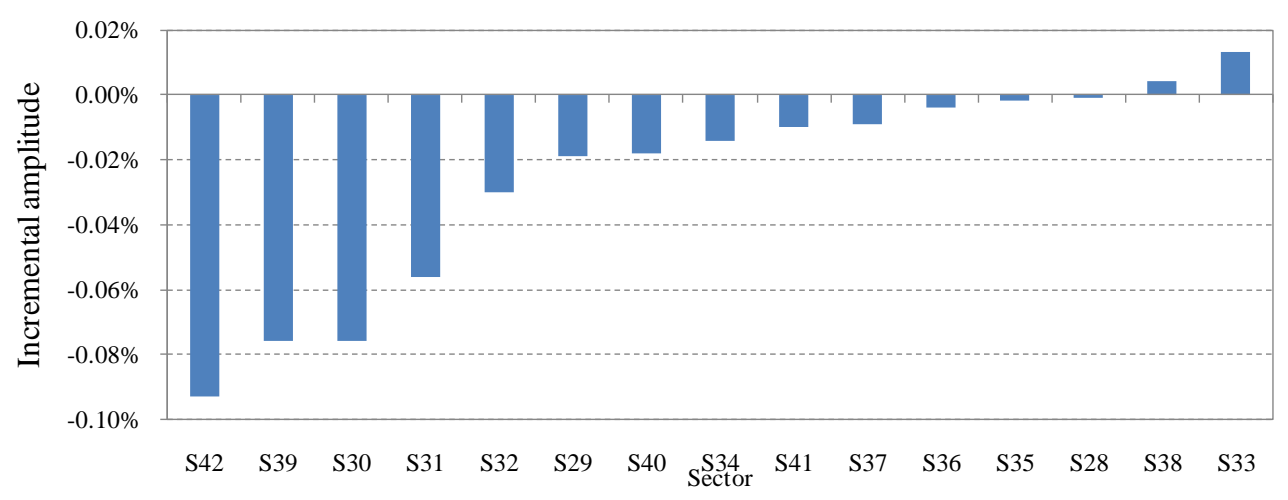

Fig. 3 The tertiary sector's change after adjustment

\section{Conclusion}

Based on the above analysis, the following conclusions can be obtained.

(1) Heavy chemical industries and light manufacturing industries have large influence in Hubei, which indicats that heavy industry cannot be changed in a short period; light manufacturing sector is also a traditional pillar industry and vital livelihood industry.

(2)A large number of sectors' interdependence on investment increases, which illustrates that economy is in a sharp raise period. in Hubei In addition, sectors which have low interdependence to investment are few, partial service industry and light manufacturing industry take the main portion.

(3) The proportions of most sectors have downward trends in Hubei. For three industries, the proportion of secondary industry will increase but the proportion of primary industry and tertiary industry will decline except real estate, resident service and others.

\section{References}

[1] X. Liu , The input-output analysis of China's industrial structure,Nanchang: Jiangxi University of Finance and Economics,2002.

[2] Y. Wang, The analysis of the input-output correlation of China's industrial structure, Management World, 4(2000):56-65.

[3] S.Yu, K.Zhu, F.Diao. A dynamic all parameters adaptive BP neural networks model and its application on oil reservoir prediction,Applied mathematics and computation, 195(1) (2008): 66-75.

[4] G.T.Guo , J.Guo , Y.M.Xi, L.Meng, Energy-Saving Effect Calculation and Implementation Strategy Study on the Industrial Structure Adjustment in Western China,China Population, Resources and Environment, 18(2008):44-49.

[5] S.Yu, et al., Carbon emission coefficient measurement of the coal-to-power energy chain in China, Applied Energy ,114 (2014): 290-300.

[6] L.Xie, Study on Hubei province industrial structure adjustment under the constraint of low carbon-based on the implied carbon input-output analysis ,Wuhan: Huazhong University of Science and Technology,2010.

[7] S. Yu, Y.-M. Wei, K. Wang,Provincial allocation of carbon emission reduction targets in China: an approach based on improved fuzzy cluster and Shapley value decomposition. Energy Policy 66 (2014): 630-644.

[8] M.Y.Zhang, Huang,X.J. Effects of industrial restructuring on carbon reduction: An analysis of Jiangsu Province, China. Energy, 44(2012):515-526.

[9] J.Song, China's industrial structure transformation by input-output analysis from 1992 to 
2002.Shenyang: Liaoning University,2007.

[10]Economic and social development outline in the Twelfth Five Year Plan of Hubei province. http://hbrb.cnhubei.com/html/hbrb/20110401/hbrb1342412.html./2011, 2.

[11]X.Zhang,Computable general equilibrium model's basic principles and programming. Shanghai people's Press, Shanghai,2010. 